\title{
An Evaluation of Strategies to Reduce Waiting Times for Total Joint Replacement in Ontario
}

Lauren E. Cipriano, BSc, BA

Institute for Technology Assessment, Massachusetts General Hospital

Boston, Massachusetts, USA

Bert M. Chesworth, $\mathrm{PhD}$

School of Physical Therapy, Faculty of

Health Sciences

Department of Epidemiology and

Biostatistics

Schulich School of Medicine \& Dentistry

University of Western Ontario

London, Canada N6A 3K7
Chris K. Anderson, PhD

School of Hotel Administration

Cornell University

Ithaca, New York14853

Gregory S. Zaric, $\mathrm{PhD}$

Richard Ivey School of Business

University of Western Ontario

London, Canada N6A 3K7

E-mail: gzaric@ivey.uwo.ca

\section{Reprints}

Gregory S. Zaric, Richard Ivey School of Business, University of Western Ontario, 1151 Richmond Street North, London, ON, Canada N6A 3K7. E-mail: gzaric@ivey.uwo.ca.

\section{Funding Disclosure}

Funded by the Ontario Ministry of Health and Long-Term Care through the Ontario Joint Replacement Registry (OJRR) Queuing Project, hosted by the London Health Sciences Centre. LEC, CKA, and GSZ were also supported by the Natural Science and Engineering Research Council of Canada (NSERC).

\section{Conflicts of Interest}

No potential conflicts exist

\section{Acknowledgments}

Preliminary results were presented at the Canadian Association for Health Services and Policy Research (CAHSPR) Annual Meeting, September 18, 2006, Vancouver, BC; at the Society for Medical Decision Making (SMDM) Annual Meeting, October 17, 2006, Boston, MA; and at the Institute for Operations Research and the Management Sciences (INFORMS) Annual Meeting, November 6, 2007, Seattle, WA.

The authors thank the OJRR, including the Managing Director, Susan Warner, the Medical Director, Dr Robert Bourne, the staff, the OJRR research subcommittee, and the queuing project advisory committee. We also thank Dr. Gillian Hawker of Women s College Hospital as well as Don DeBoer and Dr. Jack Williams of the Institute of Clinical Evaluative Sciences for providing some of the simulation model inputs.

\section{Counts}

Words: 2,791, Pages: 26, References: 47, Figures: 3, Tables: 2

Running Head: Strategies to reduce waiting times for total joint replacement 


\title{
An Evaluation of Strategies to Reduce Waiting Times for Total Joint Replacement in Ontario
}

\begin{abstract}
Background: In 2005, the median waiting time for total hip and knee joint replacements in Ontario was greater than 6 months, which is considered longer than clinically appropriate. Demand is expected to increase and exacerbate already long waiting times. Solutions are needed to reduce waiting times and improve waiting list management.

Methods: We developed a discrete event simulation model of the Ontario total joint replacement system to evaluate the effects of 4 management strategies on waiting times:

(1) reductions in surgical demand; (2) formal clinical prioritization; (3) waiting time guarantees; and (4) common waiting list management.

Results: If the number of surgeries performed increases by less than $10 \%$ each year, then demand must be reduced by at least $15 \%$ to ensure that, within 10 years, $90 \%$ of patients receive surgery within their maximum recommended waiting time. Clinically prioritizing patients reduced waiting times for high-priority patients and increased the number of patients at all priority levels who received surgery each year within recommended maximum waiting times by $9.3 \%$. A waiting time guarantee for all patients provided fewer surgeries within recommended waiting times. Common waiting list management improved efficiency and increased equity in waiting across regions.
\end{abstract}

Discussion: Dramatically increasing the supply of joint replacement surgeries or diverting demand for surgeries to other jurisdictions will reduce waiting times for total joint replacement surgery. Introducing a strictly adhered to patient prioritization scheme 
will ensure that more patients receive surgery within severity-specific waiting time targets. Implementing a waiting time guarantee for all patients will not reduce waiting times-it will only shuffle waiting times from some patients to others. To reduce waiting times to clinically acceptable levels within 10 years, increases in the number of surgeries provided greater than those observed historically or reductions in demand are needed.

Key Words: queuing, waiting time guarantees, patient prioritization, waiting list management, total joint replacement 
Long waiting times for elective surgical procedures, such as total joint replacement (TJR), are a health policy concern in many OECD countries. ${ }^{1}$ Total hip and total knee replacement surgeries are clinically-effective and cost-effective interventions. ${ }^{2-5}$ Long waiting times for TJR affect quality of life ${ }^{6,7}$ and have many economic consequences. ${ }^{7-10}$ Several initiatives to reduce waiting times for TJR surgery have been attempted around the world with varying success. However, waiting list reduction programs are expensive and no clear solution has been identified.

In Ontario, Canada, waiting times for elective total hip and total knee replacements increased between 2001 and $2005 .{ }^{11}$ In 2005 , the median waiting time for total hip replacement was over 5 months and the median waiting time for total knee replacement was 8 months. ${ }^{11}$ Median waiting times vary widely across the province: from 4 to 9 months for total hip replacement and from 6 to 11 months for total knee replacement. ${ }^{11}$ Demand for TJR is expected to increase substantially due to changing demographics, ${ }^{2,12}$ socioeconomic factors, ${ }^{13,14}$ increasing rates of obesity, ${ }^{15,16}$ and arthritis, ${ }^{12}$ expanded clinical criteria for eligibility, ${ }^{2,17,18}$ and patients' increased willingness to undergo surgery. ${ }^{13,19}$ Demand for revision surgery will likely increase as more TJR are performed on younger patients. ${ }^{17,18}$

Widespread concern exists as to whether patients are able to access TJR within a clinically acceptable time frame. ${ }^{11,20-22}$ The current federal waiting time benchmark for TJR is 6 months from the date of decision to have surgery until the surgery is performed. ${ }^{23}$ Several clinical organizations define the maximum recommended waiting times for high, intermediate, and low- priority patients as 1 month, 3 months, and 6 months from the decision to have surgery, respectively. ${ }^{20,24,25}$ 
TJR is a publicly insured service in Ontario. The Ministry of Health and Long-Term Care determines the maximum number of surgeries that can be performed each year and allocates funding across the province. Between 1995 and 2004 the number of primary and revision TJR surgeries performed in Ontario increased by approximately $5.9 \%$ annually. ${ }^{11}$ To reduce waiting times, the number of elective surgeries increased by $16.4 \%$ in $2005 .{ }^{11}$ One study showed that if $16 \%$ increases could be maintained for several years then, within 7 years, $90 \%$ of patients would receive surgery within 6 months of their decision to have surgery. ${ }^{26}$ However, human resource shortages in orthopedics, ${ }^{27}$ anesthesiology, ${ }^{28}$ and nursing ${ }^{29}$ may prevent this high level of sustained growth.

We used a discrete event simulation model of the Ontario TJR system to evaluate several strategies for reducing waiting times including: (1) reductions in demand for surgery; (2) patient prioritization; (3) waiting time guarantees; and (4) common waiting list management.

\section{Methods}

We used a discrete event simulation model which has been described in detail elsewhere 26 Surgeons in Ontario were grouped into 25 service providing regions: 11 teaching hospitals and 14 groups of community hospitals organized on the basis of Ontario's 14 Local Health Integration Networks. ${ }^{30}$

The Ontario Joint Replacement Registry (OJRR) was a clinical registry that collected demographic, medical, surgical, and outcomes information on patients who received TJR in Ontario from 1999 to 2006 . We used data from the OJRR to estimate the number of patients waiting for surgery in each region, the number of new patients joining the waiting lists of 
each region each month and the travel patterns of patients, as well as patient acuity and demographic information.

The simulation model started on March 31, 2005 with 26,583 patients waiting across the province and progressed in 1-month intervals for 10 years. Each month the following actions occurred in sequence in each region: (1) the number of patients who decided to have surgery and the amount of surgical capacity available in each region was determined; (2) new patients were added to the end of each region's waiting list; (3) patients on each list were sorted based on clinical severity and length of wait; and (4) patients at the top of each list were removed. The waiting time was the number of months between joining the waiting list for surgery and receiving the surgery. Each scenario was simulated 100 times.

\section{Results}

\section{Reducing Demand and Increasing Supply}

To assess the impact of demand reduction policies we reduced total demand projected each year and estimated the amount of time required to reduce waiting times enough that $90 \%$ of patients received surgery within their recommended maximum waiting time (Table 1). With no reduction in demand and the number of elective surgeries available growing at $14 \%$ annually, it would take 9.5 years to meet this target. When demand was reduced by $5 \%$ and $10 \%$, the timelines were reduced by approximately 1 and 2 years, respectively. When demand was reduced by $15 \%, 20 \%$, and $25 \%$, the timelines for achieving the target were reduced by 2 to 5 years depending on the rate at which the number of elective surgeries available increased. Even when demand was reduced by $25 \%$ 
and the number of surgeries available each year grew by $16 \%$, a minimum of 4.5 years was required to achieve the $90 \%$ target.

\section{Patient Prioritization}

We compared 2 methods of prioritizing patients within each region: status quo, defined as a mixture of clinical prioritization and time already waited; and strict clinical prioritization, in which higher priority patients always received surgery before lower priority patients and patients with equal clinical priority received surgery on a first-come first served basis (Fig. 1).

In the first 5 years after the implementation of strict clinical prioritization, the average number of high- and intermediate-priority patients who received surgery within their maximum recommended waiting time increased, whereas the average number of lowpriority patients who received surgery within 6 months decreased. The net effect of changing from the status quo to a clinical prioritization policy was that, on average, $9.3 \%$ more patients received surgery within their maximum recommended waiting time each year (Table 2).

\section{Waiting Time Guarantees}

We compared the base case, with no waiting time guarantee, to 3 scenarios in which waiting time guarantees were implemented at the end of the third year (Fig. 2). The waiting time guarantees evaluated were (1) "high-priority patients must receive surgery within 3 months"; (2) "high- and intermediate-priority patients must receive surgery within 3 months"; and (3) "all patients must receive surgery within 6 months." We assumed that all surgeries would continue to be provided in Ontario and that the total number of surgeries available for the year would not change as a result of the guarantee. 
With guarantee 1 or 2, waiting times decreased for the targeted population, but increased for the remaining patient population. During the first 5 years after implementation, the net effect of changing from the status quo to guarantee 1 was that $0.6 \%$ fewer patients overall received surgery within their maximum recommended waiting time on average each year (Table 2). However, implementing guarantee 2 resulted in $6.1 \%$ more patients receiving surgery within their maximum recommended waiting time annually, averaged over the first 5 years of the guarantee.

Under guarantee 3, waiting times were reduced for low-priority patients at the expense of waiting times for the higher priority patient groups. During the first 5 years of this policy, the average effect of this guarantee was that $1.1 \%$ fewer patients received surgery within their maximum recommended waiting time each year.

\section{Common Waiting Lists}

We compared the base case with 25 regional queues to a scenario in which there was one common waiting list for the entire province (Fig. 3). In the common waiting list system, there was a short-term reduction in the proportion of patients who received surgery within their maximum recommended waiting time. During this period, the regional variation in waiting times was reduced. In the long-term, $90 \%$ of patients received surgery within their maximum recommended waiting time approximately 1 year earlier.

\section{Sensitivity Analysis}

We varied the length of the initial waiting list by $\pm 20 \%$ (from 21,235 to 31,489 ) and varied the annual increase in demand from $4 \%$ to $14 \%$. Waiting time targets were met sooner with either a shorter initial waiting list or a lower rate of new patient arrivals to the 
waiting list, and later with either a longer initial waiting list or a higher rate of new patient arrivals.

We repeated the clinical priority and waiting time guarantee analyses using alternate distributions of patient severity. Holding the proportion of intermediate priority patients constant at 35\%, we varied the proportion of high priority patients between $10 \%$ and $22 \%$ (base case $=16.0 \%$ ) and varied the proportion of low priority patients between $55 \%$ and $43 \%$ (base case $=49 \%$ ). We observed a relationship between the size of the group targeted to receive priority service, the benefits for that group, and the consequences for the nonpriority service group. When the size of group receiving priority service increased (decreased), the average waiting time benefit in that group decreased (increased) and the waiting time penalty for everyone else increased (decreased).

\section{Discussion}

\section{Reducing Demand and Increasing Supply}

We predict that the number of TJR surgeries provided in Ontario must increase by at least $12 \%$ annually to reduce waiting times enough that, within 10 years, $90 \%$ of patients will receive surgery within the federal benchmark of 6 months. If the timeline for achieving this benchmark is shorter or the ability of regions to perform more surgeries is limited then substantial demand reduction or diversion to other jurisdictions must take place. Until the waiting time guarantee applied to an individual patient, the patient's position on the list was determined using the status quo method. Thus, in a scenario in which no patient waited longer than the guaranteed period, patients would be seen in the same order as a scenario in which there was no guarantee policy. 
Demand for TJR can be reduced in many different ways although none is perfect. Primary prevention, such as reducing rates of obesity, may provide reductions in demand, but only in the long-term. Explicit rationing based on clinical criteria could reduce demand. However, the population eligible for TJR is constantly being expanded by new clinical evidence. ${ }^{18}$ Regardless of how demand is reduced, our results suggest that the reduction will need to be large and sustained for several years to have any long-term impact on waiting times.

Permitting patients to obtain third-party insurance for TJR in a private setting may divert some patients out of the public system. However, this may exacerbate human resource shortages by also diverting orthopedic surgeons, anesthesiologists, and nurses out of the public service. ${ }^{27-29}$ Diversion of patients to other jurisdictions with excess capacity has been used in Ontario31 and British Colombia ${ }^{32}$ for other medical treatments and surgical procedures. Since all Canadian provinces currently have long waiting times for TJR any diversion would likely be to the United States. It is not known if primary TJR for Canadian patients, performed in the United States, would be cost effective. However, several US studies have found TJR to be cost effective ${ }^{4,5,32}$ and 1 Canadian study found that reducing waiting times for revision hip surgery can be cost saving. ${ }^{34}$

\section{Patient Prioritization}

Clinical prioritization guidelines are available but they are not strictly adhered to in practice for several reasons including accommodating patient preferences and caregiving obligations, variation in interpretations of the guidelines, variations in case-mix, and preferential treatment of some patients over others. ${ }^{20,24,25,35-38}$ We compared a strictly 
adhered to prioritization policy versus the status quo, in which each surgeon interprets and applies the prioritization guidelines independently. Compared with waiting time guarantees and common waiting list approaches, strict adherence to patient prioritization yielded the greatest improvement in waiting times for high and intermediate priority patients.

\section{Waiting Time Guarantees}

Waiting time guarantees were proposed in the Kirby report ${ }^{39}$ and have since been widely debated. ${ }^{40-44}$ Our analysis demonstrated that clinical prioritization may be sacrificed when a guarantee policy targets all patient groups. This is because providing surgery within the guaranteed time to low-priority patients causes delays for high-priority patients. By sacrificing clinical prioritization for the waiting time guarantee policy, fewer patients overall received care within their maximum recommended waiting time. Our observations are consistent with observed outcomes when waiting time guarantees have been implemented. Surgeons in Sweden abandoned the mandated waiting time guarantee to ensure that they could prioritize on a clinical basis when simultaneously faced with a waiting time guarantee and volume constraints ${ }^{45}$ In addition, concerns have been raised in the U.K. that in an effort to meet waiting time targets surgeons were no longer able to schedule patients in the order indicated by clinical priority ${ }^{46}$ Although the number of longwaiting patients declined, it came at the expense of the health of more urgent patients. ${ }^{46}$

\section{Common Waiting Lists}

The use of common waiting lists was recommended by the federal advisor on waiting times. ${ }^{41}$ We found that common waiting lists resulted in increased efficiency, increased equity in waiting times across regions, and reduced waiting times in the long 
term. In the regional waiting list system, large variation in waiting times across regions persisted, whereas in the common waiting list system, variation in waiting times across regions was minimized resulting in similar severity-specific waiting time distributions across regions. Once the variation across regions was diminished, waiting times were reduced in all regions simultaneously. Common waiting list management resulted in achieving waiting time targets 1 year earlier, and thus had approximately the same effect as reducing demand by $5 \%$ each year. This occurred because there were fewer instances of an allocated surgery not being used.

Independently managed lists result in instances of patients with lesser need receiving care faster than patients with greater need due to the case mix and prioritization practice of different surgeons and may contribute to the appearance of inequity. We did not have sufficiently detailed information to model at the level of the individual surgeon, even though this is the level at which waiting lists are maintained. However, we would expect benefits from any degree of waiting list sharing, such as from physicians to groups of physicians within the same hospital, within the same region, or in geographically close regions. Common waiting list management may lead to reductions in the inequities across practices and reductions in waiting times for patients in the highest clinical priority groups.

\section{Limitations and Conclusions}

Our model has limitations. It is a high-level simplification of a complex system. We did not model the behaviors of individual patients and surgeons nor the specific capacity limitations faced by each hospital and each region. Instead we simulated at the regional level and used statistical rather than behavioral models of patient actions and surgeon waiting list management strategies. We did this because reporting by surgeons to the OJRR 
was voluntary and completion rates varied widely. We adjusted volumes in under-reported regions according to submission rates and sought external validation for inputs whenever available. To mitigate the weaknesses of the OJRR dataset, we performed sensitivity analysis on parameters generated from the OJRR. In addition, we did not consider the possibility that the condition of patients who joined the waiting list in a low-priority group would eventually deteriorate causing them to become high- priority patients.

Two of the strategies evaluated-waiting time guarantees and clinical prioritization—only change the order in which patients are seen. However, they do not change and should not be expected to change average waiting times for all patients. According to basic queuing theory, this should only occur if capacity increases, demand decreases, or uncertainty around capacity or demand decreases.47 Common management of waiting lists also does not change capacity. The gains observed when waiting lists are shared is due to a better match between supply and demand at all times. This gives the appearance of increased capacity but the reduction in waiting times is actually the result of increased system efficiency caused by less unused capacity.

The results shown here are not precise predictions of the future. Instead they highlight the differences between strategies. Significant reductions in demand or diversion to other jurisdictions were needed to have a noticeable impact on the time required to meet waiting time goals. Strict clinical prioritization resulted in the greatest improvement in the number of patients receiving surgery within maximum recommended waiting times. Waiting time guarantees for all patients, a politically popular strategy, had a small overall waiting time benefit that came at the expense of the highest priority patients. Common waiting lists reduced variation in waiting times between regions and reduced waiting times 
in the long run. If the objective of policy-makers is to maximize the number of patients who receive surgery within their recommended maximum waiting time, then diversion of patients to jurisdictions with excess capacity and enhanced use of prioritization tools are likely to be more effective than waiting time guarantees. 


\section{REFERENCES}

1. Hurst J, Siciliani L. OECD Health Working Papers No. 6: Tackling excessive waiting times for elective surgery: a comparison of policies in twelve OECD countries. Paris: Directorate for Employment, Labour, and Social Affairs; 2003.

2. NIH consensus statement on total hip replacement. NIH Consens State Sci Statements. $1994 ; 12: 1-31$.

3. NIH consensus statement on total knee replacement. NIH Consens State Sci Statements. $2003 ; 20: 1-32$.

4. Chang RW, Pellisier JM, Hazen GB. A cost-effectiveness analysis of total hip arthroplasty for osteoarthritis of the hip. JAMA. 1996; 275:858-865.

5. Lavemia CJ, Guzman JF, Gachupin-Garcia A. Cost effectiveness and quality of life in knee arthroplasty. Clin Orthop Relat Res. 1997; 345: 134-139.

6. Williams JI, Llewellyn Thomas H, Arshinoff R, et al. The burden of waiting for hip and knee replacements in Ontario. Ontario Hip and Knee Replacement Project Team. J Eval Clin Pract. 1997; 3:59-68.

7. Rigge M. Quality of life of long wait orthopaedic patients before and after admission: a consumer audit. Qual Health Care. 1994; 3:159-163.

8. Rossvoll I, Benum P, Bredland TR, et al. Incapacity for work in elective orthopaedic surgery: a study of occurrence and the probability of returning to work after treatment. $J$ Epidemiol Community Health. 1993; 47:388-394.

9. Hertzman P, Johnsson R, Lindgren B. Cost of sick leave for total hip replacement. Acta Orthop Scand. 1988; 59:266-269. 
10. Johnsson R, Persson BM. Occupation after hip replacement for arthrosis. Acta Orthop Scand. 1986; 57:197-200.

11. Bourne RB, DeBoer D, Hawker GA, et al. Chapter 5. Total Hip and Knee Replacement. In: Tu JV, Pinfold SP, McColgan P, et al, eds. Access to Health Services in Ontario: ICES Atlas Update. Toronto, Ontario: Institute for Clinical Evaluative Sciences; 2006.

12. Perruccio AV, Badley EM, Guan J. Chapter 2: Burden of Disease. In: Badley EM, Glazier R, eds. Arthritis and Related Conditions in Ontario: ICES research atlas. 2nd ed. Toronto, Ontario: Institute for Clinical Evaluative Sciences; 2004.

13. Hawker GA, Wright JG, Coyte PC, et al. Differences between men and women in the rate of use of hip and knee arthroplasty. N Engl J Med. 2000; 342:1016-1022.

14. Hawker GA, Wright JG, Glazier RH, et al. The effect of education and income on need and willingness to undergo total joint arthroplasty. Arthritis Rheum. 2002; 46:3331-3339.

15. Karlson EW, Mandl LA, Aweh GN, et al. Total hip replacement due to osteoarthritis: the importance of age, obesity, and other modifiable risk factors. Am J Med. 2003; 114:93-98. 16. Gelber AC, Hochberg MC, Mead LA, et al. Body mass index in young men and the risk of subsequent knee and hip osteoarthritis. Am J Med. 1999; 107:542-548.

17. Dunbar MJ, Malloy L, Blake JT, et al. Department of Surgery, Wait List Management Project, Orthopaedic Pilot Project. Halifax: Queen Elizabeth II Health Sciences Center; January 2004.

18. Brander VA, Malhotra S, Jet J, et al. Outcome of hip and knee arthroplasty in persons aged 80 years and older. Clin Orthop Relat Res. 1997; 345:67-78. 
19. Hawker GA, Wright JG, Badley EM, et al. Perceptions of, and willingness to consider, total joint arthroplasty in a population-based cohort of individuals with disabling hip and knee arthritis. Arthritis Rheum. 2004; 51:635-641.

20. Wait Time Alliance for Timely Access to Health Care. It's about time! Achieving benchmarks and best practices in wait time management. Ottawa, Ontario: Canadian Medical Association; August 2005.

21. Chaoulli v. Quebec (Attorney General). Supreme Court Reports, Volume 1: Supreme Court of Canada; 2005.

22. Noseworthy TW, McGurran JJ, Hadom DC. Waiting for scheduled services in Canada: development of priority-setting scoring systems. J Eval Clin Pract. 2003; 9:23-31.

23. First ever common benchmarks will allow Canadians to measure progress in reducing wait times. Press Release, December 12, 2005. Available at:

http://www.health.gov.on.ca/english/media/news_releases/archives/nr_05/nr_l 21205.html.

24. Chesworth B, Warner S, Bourne R. Guideline for Wait Time Thresholds for Total Hip and Knee Replacement Surgery Based on Severity: Detailed Report. London: Ontario Joint Replacement Registry; 2006.

25. Rumble T, Kreder HJ. Report of Benchmarks for Wait Times: The National Standards Committee. Canada: Canadian Orthopaedic Association; March 2005.

26. Cipriano LE, Chesworth BM, Anderson CK, et al. Predicting joint replacement waiting times. Health Care Manag Sci. 2007; 10:195-215.

27. Shipton D, Badley EM, Mahomed NN. Critical shortage of orthopaedic services in Ontario, Canada. J Bone Joint Surg Am. 2003; 85A: 1710—1715. 
28. Engen DA, Morewood GH, Ghazar NJ, et al. A demand-based assessment of the Canadian anesthesia workforce - 2002 through 2007. Can J Anaesth. 2005; 52:18-25.

29. O’Brien-Pallas L, Alksnis C, Wang S. Bringing the Future into Focus: Projecting RN

Retirement in Canada. Canada: Canadian Institute for Health Information; 2003.

30. Local Health Integration Networks: Geographic Boundaries and Supporting

Information. May 2006. Available at: http://www.health.gov.

on.ca/transformation/lhin/lhinmap_mn.html. Accessed June 28, 2006.

31. Fitch MI, Gray RE, McGowan T, et al. Travelling for radiation cancer treatment: patient satisfaction. Can Oncol Nurs J. Spring. 2005; 15:107119.

32. Katz SJ, Mizgala HF, Welch HG. British Columbia sends patients to Seattle for coronary artery surgery. Bypassing the queue in Canada. JAMA. 1991; 266:1108-1111.

33. Brauer CA, Rosen AB; Olchanski NV, et al. Cost-utility analyses in orthopaedic surgery. J Bone Joint Surg Am. 2005; 87:1253-1259.

34. Saleh KJ, Wood KC, Gafhi A, et al. Immediate surgery versus waiting list policy in revision total hip arthroplasty. An economic evaluation. J Arthroplasty. 1997; 12:1-10. 35. Gross AE. Report of the Total Hip and Knee Joint Replacement Expert Panel: Total Hip and Knee Joint Replacement Expert Panel; September 2005.

36. Moving Forward. February 28, 2005. Available at: http://www.wcwl.org/media/pdf/news/moving_forward/report.pdf. Accessed February $16,2006$.

37. Kelly KD, Voaklander D, Kramer G, et al. The impact of health status on waiting time for major joint arthroplasty. J Arthroplasty. 2000; 15: 877-883. 
38. Kelly KD, Voaklander DC, Johnston WC, et al. Equity in waiting times for major joint arthroplasty. Can J Surg. 2002; 45:269-276.

39. Kirby MJL. Volume Six: Recommendations for Reform. Washington, DC: The Senate; 2002.

40. Kirby MJL. The Only Two Options for Funding the Wait-Time Guarantee. Montreal: Institute for Research on Public Policy; 2006.

41. Postl BD. Final Report of the Federal Advisor on Wait Times. Ottawa: Health Canada; June 2006.

42. O’Neill J. No hard promise for wait time guarantees. National Post. February 5, 2007. 43. Lindgren A. Provinces skeptical of wait-time guarantees: Federal promise just not possible, critics say. The Ottawa Citizen. February 10, 2007.

44. Blackwell T. Heath wait-times a gimmick, critics say. National Post. April 5, 2007. 45. Hanning M, Spangberg UW. Maximum waiting time-a threat to clinical freedom? Implementation of a policy to reduce waiting times. Health Policy. 2000; 52:15-32. 46. Appleby J, Boyle S, Devlin N, et al. Do English NHS waiting time targets distort treatment priorities in orthopaedic surgery? J Health Serv Res Policy. 2005; 10:167-172. 47. Hillier F, Lieberman G. Introduction to Operations Research. 6th ed. McGraw-Hill, Inc.; 1995. 


\section{Figure Legends}

Figure 1. The proportion of TJR patients who received surgery within the maximum recommended waiting time for each level of clinical severity. The 2 scenarios differ in the method of choosing which patient on the list will receive the next surgery: status quo ( $\bullet$ ); clinical severity at the time of decision (o). In both scenarios, the number of elective surgeries available to be performed increased by $16 \%$ each year. A, The proportion of high priority patients.

Figure 2. The proportion of TJR patients who received surgery within the maximum recommended waiting time for each level of clinical severity. The scenarios differ in the presence and characteristics of the waiting time guarantee implemented: no guarantee (status quo, $\diamond$ ); guarantee (1), "all high priority patients must receive surgery within 3 months" (A); guarantee (2), "All high and intermediate priority patients must receive surgery within 3 months" ( $\square$ ); guarantee (3), "All patients must receive surgery within 6 months" (X). In all 4 scenarios, the number of elective surgeries available to be performed increased by $16 \%$ each year. Column 1, panels A, B, and C: Guarantee 1 vs. the status quo. Column 2, panels D, E, and F: Guarantee 2 vs. the status quo. Column 3, panels G, H, and I: Guarantee 3 vs. the status quo. Row 1, panels A, D, and G: The proportion of high priority patients who received surgery within 1 month. Row 2, panels B, E, and H: The proportion of intermediate priority patients who received surgery within 3 months. Row 3 , panels $\mathrm{C}, \mathrm{F}$, and I: The proportion of low priority patients who received surgery within 6 months, comparing each guarantee to the status quo across the row. 
Figure 3. The proportion of all TJR patients who received surgery within the maximum recommended waiting time for each level of clinical severity. The scenarios differ in the level of waiting list sharing: regionally organized ( $)$; provincially organized (X). in both scenarios, the number of elective surgeries available to be performed increased by $16 \%$ each year. A, The proportion of high priority patients who received surgery within 1 month. B, The proportion of intermediate priority patients who received surgery within 3 months. C, The proportion of low priority patients who received surgery within 6 months. 


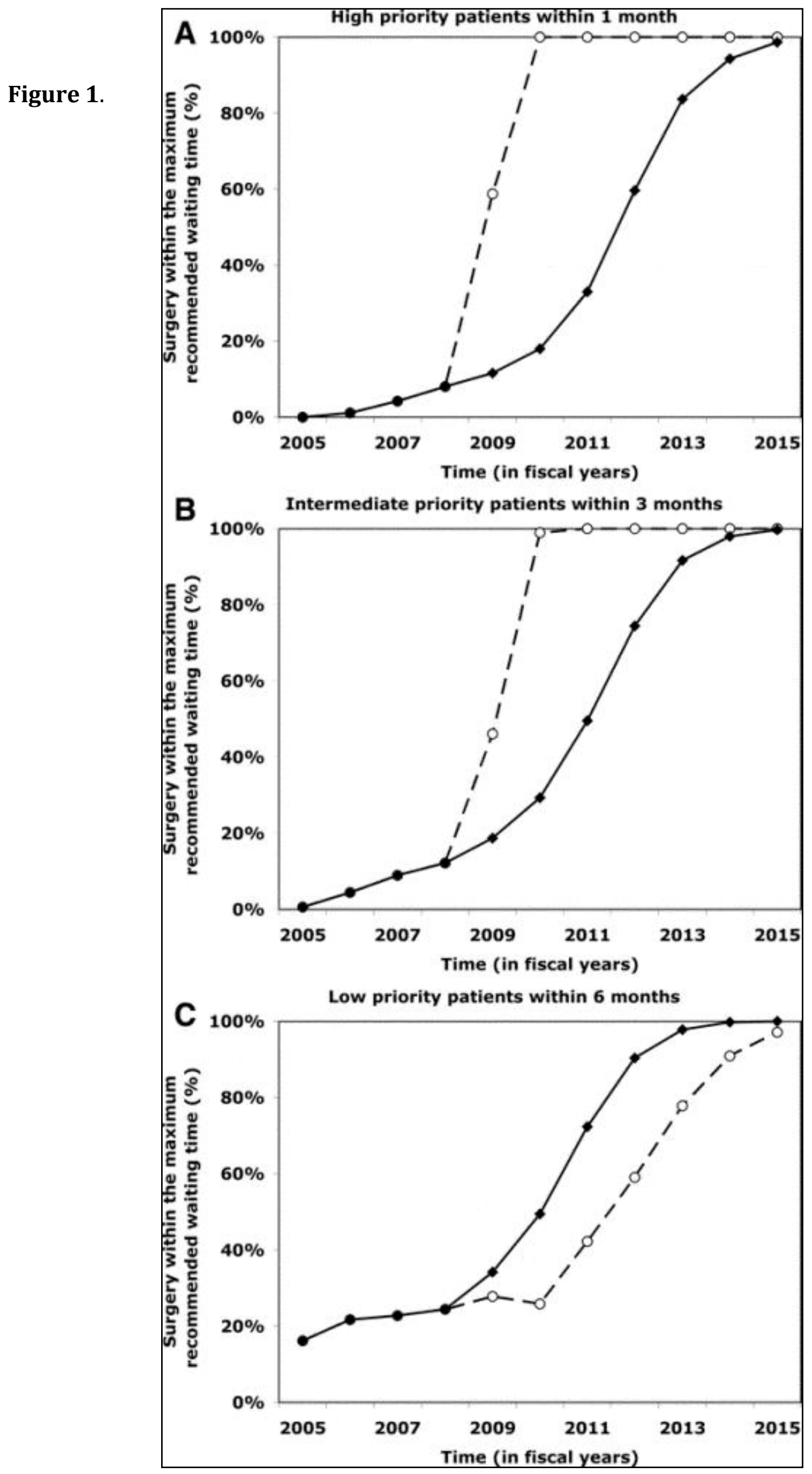


Figure 2.
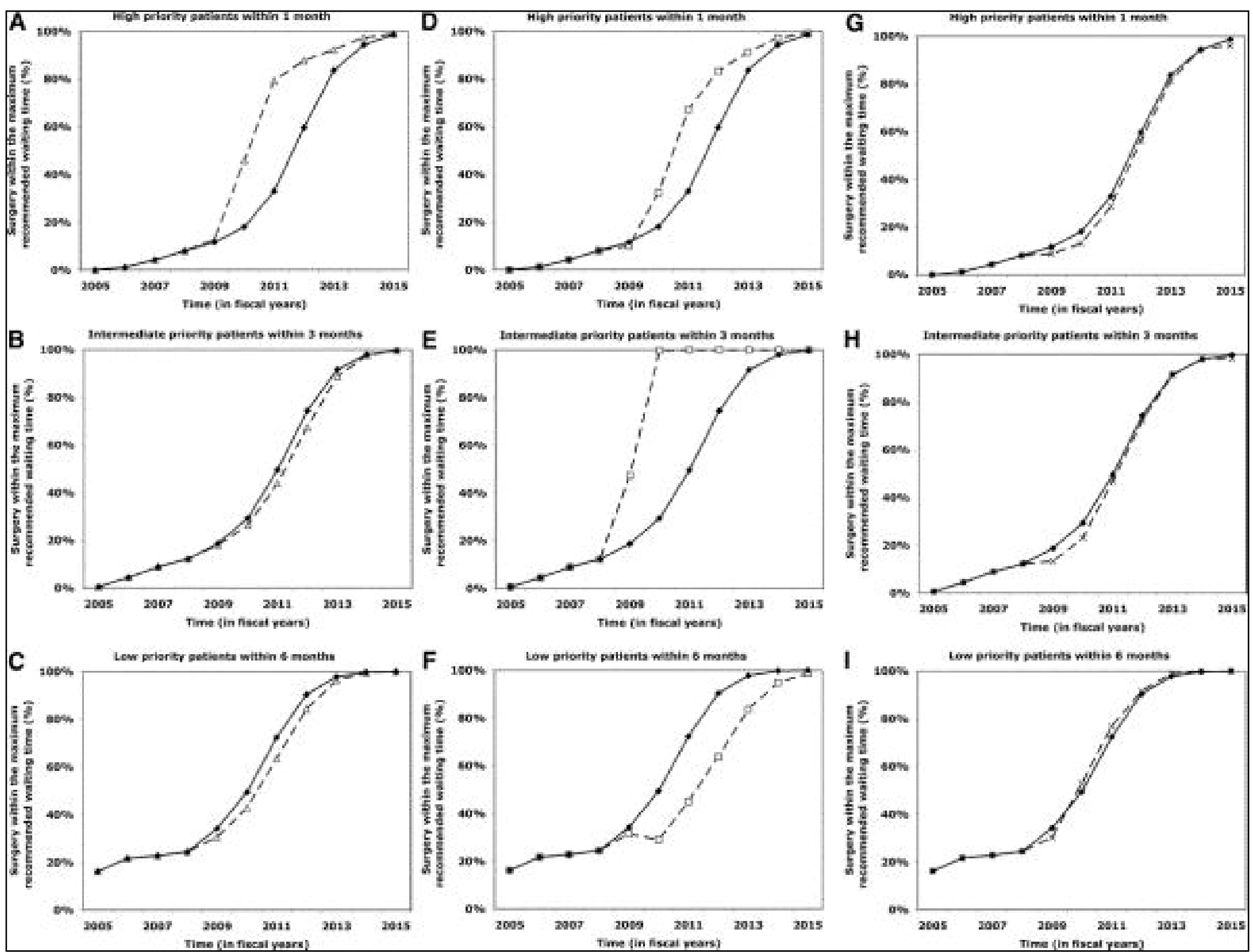
Figure 3
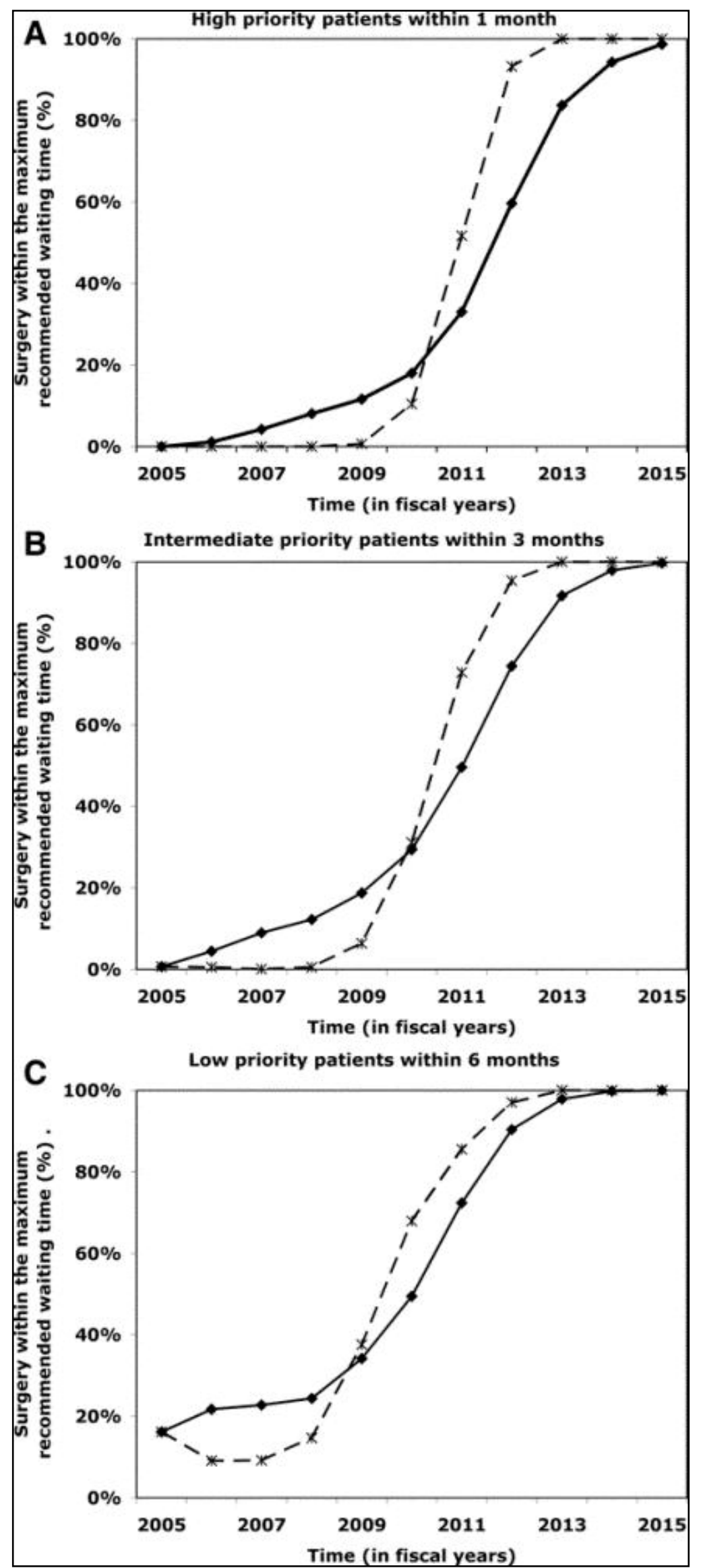
Table. 1. The Approximate Number of Years Required Until 90\% of Total Joint Replacement Surgeries are Provided Within the Priority-Specific Recommended Maximum Waiting Time.

\begin{tabular}{lccccc}
\hline & $\begin{array}{c}\text { Average Annual } \\
\text { Demand }\end{array}$ & \multicolumn{4}{c}{$\begin{array}{c}\text { Annual Increase in Elective } \\
\text { Surgeries Available }\end{array}$} \\
\cline { 2 - 6 } $\begin{array}{c}\text { Reduction* (\%) } \\
\text { Increase (\%) }\end{array}$ & $\mathbf{1 0 \%}$ & $\mathbf{1 2 \%}$ & $\mathbf{1 4 \%}$ & $\mathbf{1 6 \%}$ \\
\hline 0 & 8.7 & $>10$ & $>10$ & 9.5 & 8 \\
5 & 8.1 & $>10$ & $>10$ & 8.5 & 7 \\
10 & 7.6 & $>10$ & 10 & 7.5 & 6.5 \\
15 & 7.0 & $>10$ & 8 & 7 & 6 \\
20 & 6.5 & 9 & 7 & 6 & 5 \\
25 & 5.9 & 7.5 & 6 & 5 & 4.5 \\
\hline & $*$ Demand reductions were evenly distributed across all priority groups and across \\
regions where patients sought care. Demand was calculated such that the projected total \\
demand was first calculated, then total projected demand was reduced by the scenario \\
specific rate.
\end{tabular}


Table 2 . Average Proportion of Patients by Priority Level Receiving Surgery Within Their Maximum Recommended Waiting Time Over the First 5 Years of Implementing the New Policy Under 5 Different Policy Options.

\begin{tabular}{|c|c|c|c|c|}
\hline Policy Optiens & $\begin{array}{c}\text { High-Priority } \\
\text { Patients }(\%) \\
\text { (Within I Month) }\end{array}$ & $\begin{array}{c}\text { Intermediate-Priority } \\
\text { Patients }(\%) \\
\text { (Within } 3 \text { Menths) }\end{array}$ & $\begin{array}{c}\text { Low-Priority } \\
\text { Patients }(\%) \\
\text { (Within } 6 \text { Mouths) }\end{array}$ & $\begin{array}{l}\text { All Patieats }(\%) \\
\text { (Within Their Respective Maximum } \\
\text { Recommended Waiting Times) }\end{array}$ \\
\hline \multicolumn{5}{|l|}{ Status quo } \\
\hline $\begin{array}{l}\text { A mixture of clinical pricritization } \\
\text { and time already waited }\end{array}$ & 41.2 & 52.7 & 68.8 & 59.0 \\
\hline \multicolumn{5}{|l|}{ Clinical prioritization } \\
\hline $\begin{array}{l}\text { Patients are served in order of } \\
\text { clinical priority regardless of time } \\
\text { already waited }\end{array}$ & 91.7 & 89.0 & 46.6 & 68.3 \\
\hline \multicolumn{5}{|l|}{ Waiting time guarantec policies? } \\
\hline $\begin{array}{l}\text { 1. High-priority patients must } \\
\text { receive surgery within } 3 \text { mo }\end{array}$ & 63.6 & 48.9 & 63.5 & 58.4 \\
\hline $\begin{array}{l}\text { 2. High- and intermediate-priority } \\
\text { patients must receive surgery } \\
\text { within } 3 \text { mo }\end{array}$ & 56.7 & 89.4 & 50.6 & 65.1 \\
\hline $\begin{array}{l}\text { 3. All patients must receive surgery } \\
\text { within } 6 \text { mo }\end{array}$ & 37.5 & 49.3 & 70.1 & 57.9 \\
\hline \multicolumn{5}{|c|}{ 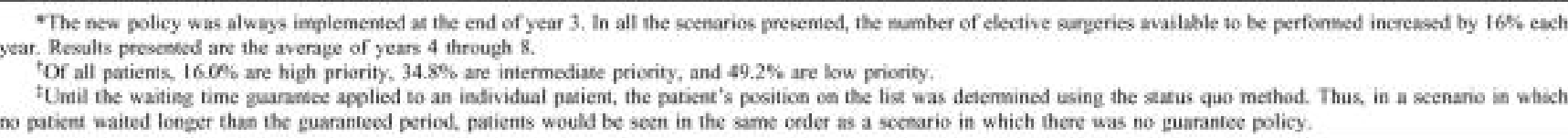 } \\
\hline
\end{tabular}

